\title{
Incidence and risk factors of spinal epidural hemorrhage after spine surgery: a cross- sectional retrospective analysis of a national database
}

\author{
Ji Hyun Park ${ }^{1}$, Sunny Park² ${ }^{2}$ and Soo An Choi $^{*^{*}}$ (D)
}

\begin{abstract}
Background: With increasing number of patients undergoing spine surgery, the spinal epidural hemorrhage (SEH) has become a growing concern. However, current studies on SEH rely on case reports or observations from a single center. Our study attempted to demonstrate the incidence rate and risk factors of SEH using a national dataset.

Methods: A total of 17,549 spine surgery cases from the Health Insurance Review and Assessment Service National Inpatient Sample of 2014 were analyzed. After evaluating the incidence of SEH based on severe cases requiring reoperation, a univariate comparison was performed. Variables found to be significant were included in a multivariable analysis model to determine the risk factors.

Results: The incidence of SEH was found to be $1.15 \%$ in Korean population, and there were no severe SEH cases. Our analysis confirmed the previous findings that lumbar surgery, intraoperative blood loss, prolonged surgical time, high blood pressure, use of nonsteroidal anti-inflammatory drugs, and concurrent bleeding factors are the risk factors of SEH. Anterior approach showed a protective effect. The use of anticoagulant demonstrated no statistical significance.

Conclusion: Although severe SEH cases were not detected, the incidence of SEH was similar to that reported in literature. Given that SEH is a rare complication of spine surgery and constitutes an important research area that needs to be studied further, our study makes a meaningful contribution based on a rigorous national level sample for the first time and provides the academic circle and health professionals with a reliable evidence of improved clinical outcomes in such cases.
\end{abstract}

Keywords: Postoperative spinal epidural hemorrhage, Postoperative spinal epidural hematoma, National claims dataset, Spine surgery, Thoromboprophylaxis, Asian population, Incidence, Risk factors

\section{Background}

Globally, spine surgery rates have drastically increased in the last two decades [1]. There are a number of reasons, such as an increased incidence of obesity, degenerative spinal conditions, and an aging population seeking better quality of life, for this increase [2]. Therefore, it has

\footnotetext{
* Correspondence: sachoi@korea.ac.kr

'College of Pharmacy, Korea University, 2511 Sejong-ro, Sejong-si 30019, South Korea

Full list of author information is available at the end of the article
}

become necessary to meet the challenging goal of improving the success rate of spine surgeries while minimizing postoperative complications.

Spinal epidural hemorrhage (SEH) manifests a bleeding in the epidural space along the spinal canal [3]. Stimulation that results in hemorrhage around the spinal cord may cause SEH; these include trauma, surgeries, tumors, use of anticoagulants, or invasive neurological procedures. SEH is mostly asymptomatic; however, in some cases, it can result in the accumulation of blood in

C C The Author(s). 2020 Open Access This article is licensed under a Creative Commons Attribution 4.0 International License, which permits use, sharing, adaptation, distribution and reproduction in any medium or format, as long as you give appropriate credit to the original author(s) and the source, provide a link to the Creative Commons licence, and indicate if changes were made. The images or other third party material in this article are included in the article's Creative Commons licence, unless indicated otherwise in a credit line to the material. If material is not included in the article's Creative Commons licence and your intended use is not permitted by statutory regulation or exceeds the permitted use, you will need to obtain permission directly from the copyright holder. To view a copy of this licence, visit http://creativecommons.org/licenses/by/4.0/ The Creative Commons Public Domain Dedication waiver (http://creativecommons.org/publicdomain/zero/1.0/) applies to the data made available in this article, unless otherwise stated in a credit line to the data. 
the epidural space that can lead to spinal cord damage, resulting in neurological deficit [4]. Asymptomatic SEH develops in $33-100 \%$ of spinal surgery cases and is known to be spontaneously absorbed postoperatively [5, 6]. Symptomatic SEH causing permanent neurologic deficit rarely develops, and the reported incidence rate is between 0 and 3\%. As the incidence of symptomatic SEH has been extremely low, most extant studies on the topic are case studies based on individual clinics [7, 8]. Far less is known on the Asian population including South Korea and Japan regarding all types of SEH, and even the exclusive diagnostic code for SEH has not yet been established $[9,10]$.

Although there is no consensus with regard to the risk factors, postoperative anticoagulant use is known to increase the incidence of SEH $[11,12]$. It is strongly recommended that patients undergoing hip or knee arthroplasty receive anticoagulants to prevent thromboembolic events; Thromboembolic events (TEs) refers to all related events which a blood clot formed in vessel slows or plugs the blood stream [13]. However, this is not the case for patients undergoing spine surgery [14]. The clinical guidelines reveal that there is insufficient evidence to decisively predict the level of risk that prophylaxis could carry; moreover, they identify patients whose benefits outweigh the risks. Consequently, anticoagulant use in patients undergoing spine surgery is left to the discretion of clinicians $[15,16]$.

More issues are to be resolved in Asian population who had rarely developed thromboembolism after operation [17]. Recent studies have found that the use of anticoagulants in Asian populations is much less than necessary, although the incidence of postoperative TEs in the Asian population is comparable to that in the Western population $[18,19]$. With the conventional clinical practice of anticoagulant use combined with the fear of developing severe $\mathrm{SEH}$, clinicians are more likely to avoid anticoagulants [20].

Considering this, a study that attempts to analyze a large dataset created by utilizing postoperative hemorrhage treatment codes on Asian population could clarify the epidemiology of epidural hemorrhage in patients undergone spine surgery. Therefore, the two main goals of this study were: to investigate the incidence of SEH by analyzing a national database, the Health Insurance Review and Assessment Service National Inpatient Sample of 2014 (HIRA-NIS-2014) and to determine the risk factors that could clearly indicate the cause of SEH development in Korean population.

\section{Methods}

National Inpatient Sample of 2014

South Korea has a National Health Insurance System (NHIS) that covers approximately $98 \%$ of the overall
Korean population, and $99 \%$ of National Health Insurance (NHI) claims data have been electronically reported since 2005. The claims data of Health Insurance Review and Assessment Service (HIRA) pertains to patients' diagnosis, treatment, surgical history, procedures performed, and prescription drug information. However, the extensive volume and complicated structure of the claims data limit research approaches. To improve accessibility for researchers to use the claims data, HIRA has established the patient sample data sets that have been validated by five different validity tests [21].

These patient sample datasets are as follows: adult patient group, pediatric patient group, all patient group, and inpatient group. The adult patient sample represents approximately 1 million patients aged $>65$ years annually ( $20 \%$ of the original data), whereas the pediatric patient sample takes into account 1.1 million patient aged $<20$ years annually ( $10 \%$ of the original data). All patient samples represents overall 1.4 million patients annually, which represents $3 \%$ of the original population. Lastly, national inpatient sample pertains to 700,000 inpatients (13\%), and approximately 400,000 outpatients (1\%) annually. All sample dataset contain sampling weights allow obtaining estimated national population. With a 95\% concordance, the estimated population and the actual population demonstrated a high level of representativeness [22].

Our study analyzed the customized NHIS dataset of HIRA National Inpatient Sample of 2014 (HIRA-NIS2014), which contains claims data from January 1, 2014 to December 31, 2014 [23]. This period is defined as the research period in this study. Sampling weights were applied to give best representative estimation of the actual population. The analysis in this study was based on the number of pertinent cases, instead of the number of patients, as one patient might undergo multiple spinal surgeries during the research period. For example, if a patient underwent two different spine surgeries during their independent hospitalizations, the detected number of pertinent cases would be two.

\section{Availability of data and materials}

The data that support the findings of this study are available from HIRA but restrictions apply to the availability of these data, which were used under license for the current study. Thus, these data are not publicly available. However, the data are available from HIRA upon reasonable request and with permission.

\section{SEH case identification}

In Korea, currently there are no disease/treatment codes that exclusively represent SEH. Based on existing studies, this study converted the diagnostic code for postoperative SEH (998.12) indicated in the International 
Statistical Classification of Diseases and Related Health Problems, 9th revision (ICD-9) to the most appropriate disease code in the 6th Korea Informative Classification of Disease (KOICD-6) codes [24]. As KOICD codes does not differentiate postoperative hematoma from hemorrhage, SEH cases in this study included both spinal epidural hemorrhage and spinal epidural hematoma.

Based on code selection recommendations from the Centers for Disease Control and Prevention/National Center for Health Statistics and KOICD, we first extracted all cases of postoperative hemorrhage and hematoma (T81 and T810), and then narrowed down to severe SEH. Severe SEH cases were defined as the ones that required medical treatment codes for the removal or drainage of hematoma in the central nervous system $[9,25]$. T81 and T810 are defined as hemorrhage and hematoma which excludes adverse effect of drug, hematoma of obstetric wound, or failure of transplanted grafts. If the SEH case also had hemorrhage controlling or hematoma drainage codes such as S4755, S4756 or S4754, it would be included in the group of severe SEH cases. Detailed information on the disease and treatment codes were listed in Supplementary Table 1.

Next, all selected cases were individually investigated by three different medical professionals for concurrent diseases, treatment provided, and medications to demonstrate detailed information on severe SEH after spine surgery during patient hospitalizations. Subsequently, all claims records of selected patients during the study period, the disease/treatment codes for the complications of surgical and medical care and postoperative disorders of the nervous system after spine surgery were examined. Detailed information on the disease and treatment codes is listed in Supplementary Table 1.

As an illustration, in a patient with spinal disease undergoing spine surgery, the incidence of postoperative hemorrhage and hematoma was first examined. Then, the intervention for postoperative SEH or spinal nerve compression was evaluated throughout the study period. If any of the codes indicated postoperative disorders of the nervous system or complication from surgical care, every detail of the case was flagged for further review. All variables for a pertinent case were relevant to the hospitalization period. Detailed information on the SEH codes is presented in Supplementary Table 1.

\section{Literature review for risk factors and spine surgery case selection}

To construct the conceptual framework of analysis, the extant studies on incidence and risk factors of SEH were extensively reviewed. The terms "(spinal epidural hematoma) AND (spine surgery) AND (risk factor)" were searched in the MEDLINE database. Simultaneously, the codes for spinal disease were referenced by literature review. In case a patient had a spinal disease code and underwent surgery in relation to the main disease, the patient was considered to have undergone spine surgery. In addition, the risk factors considered in this study were based on the results of the literature review. For example, the definition of extended surgery hours ( $\geq 2 \mathrm{~h}$ ) and loss of blood were based on the literature search. The use of nonsteroidal anti-inflammatory drugs (NSAIDs) was defined as the administration of NSAIDs at any time during the hospitalization. The total medical cost was the total expenditure on the hospitalization in a case that was claimed by the medical institution. Insurance types were categorized as the NHI and Medical Aid/Veterans Medical Benefits. Blood loss was calculated by the blood transfusion claims codes of the case. Type of hospitals was classified into two categories: general hospitals (e.g., tertiary academic hospitals and general hospitals) and small hospitals (e.g., hospitals and clinics). The location of hospitals was divided into three categories: metropolitan area (Seoul), other metropolitan areas(e.g., Busan, Daegu, Incheon, Gwangju, Daejon, Ulsan and Sejong), and rural area (all other locations). The duration of hospital stay was calculated by subtracting the admission date from the discharge date.

In case a patient record included any invasive procedures such as lumbar puncture, myelography, and epidural anesthesia, then it was considered that the patient underwent invasive procedures. If a patient had thrombocytopenia or coagulation factor deficiency, the patient was regarded to have a bleeding factor. Trauma case was determined if the patient was admitted through the emergency department.

\section{Statistical methods and data analyses}

After establishing the analytical dataset containing the variables identified as risk factors, we conducted a descriptive analysis. A pairwise correlation test was applied to determine the level of correlation among the set of variables included in the study model. A chi-square test and independent two-sample t-test were used accordingly to determine if there was any significant association between a set of independent variables and both categorical and continuous dependent variables. As the final step, a multivariate logistic regression was utilized prior to which multicollinearity was examined by referring to the variance inflation factor. Data with a variance inflation factor of $>5$ were excluded from the model. In the multivariate logistic regression model, this study tries to identify factors that are associated with the incidence of SEH. Sampling weight was used to obtain better estimation of the original population. All statistical analyses were performed using Stata 14.0 [26]. 


\section{Results}

\section{Spine surgery and SEH case estimation}

Based on the inpatient records, out of a total of 31,964 , 373 cases, there were 17,549 cases of spinal surgery in 2014. As shown in Fig. 1, the total number of cases of hemorrhage and hematoma occurring after spine surgery was $201(1.15 \%)$, and there were no severe SEH cases as assessed by the codes of hemorrhage evacuation, decompression, or postoperative complication caused by spine surgery.

\section{SEH risk factors suggested by recent research}

Based on the extensive review of recent studies, Table 1 presents the incidence rate and risk factors of SEH. The incidence rate varied from 0 to $23.6 \%$ owing to the differences in diagnoses, detection methods, and sample sizes. The identified risk factors are as follows: obesity, hypertension, diabetes, bleeding factors, use of anticoagulant/antiplatelet medications, alcohol consumption, malignancy, previous surgeries, female sex, surgery type (lumbar) and approach, age of 65 and above years, use of NSAIDs, blood loss, trauma, prolonged surgical time, and invasive procedures.

\section{Characteristics of cases}

Patient characteristics were obtained from the 17,549 spinal surgery cases (201 patients with SEH and others). The values for age, total medical cost, and duration of hospital stay were greater for SEH cases than for nonSEH cases. Lumbar spine surgery type and posterior approach showed significance in the univariate analysis. Of all SEH cases, 199 involved treatment with NSAIDs. Among all patients with SEH, 14 underwent surgery for

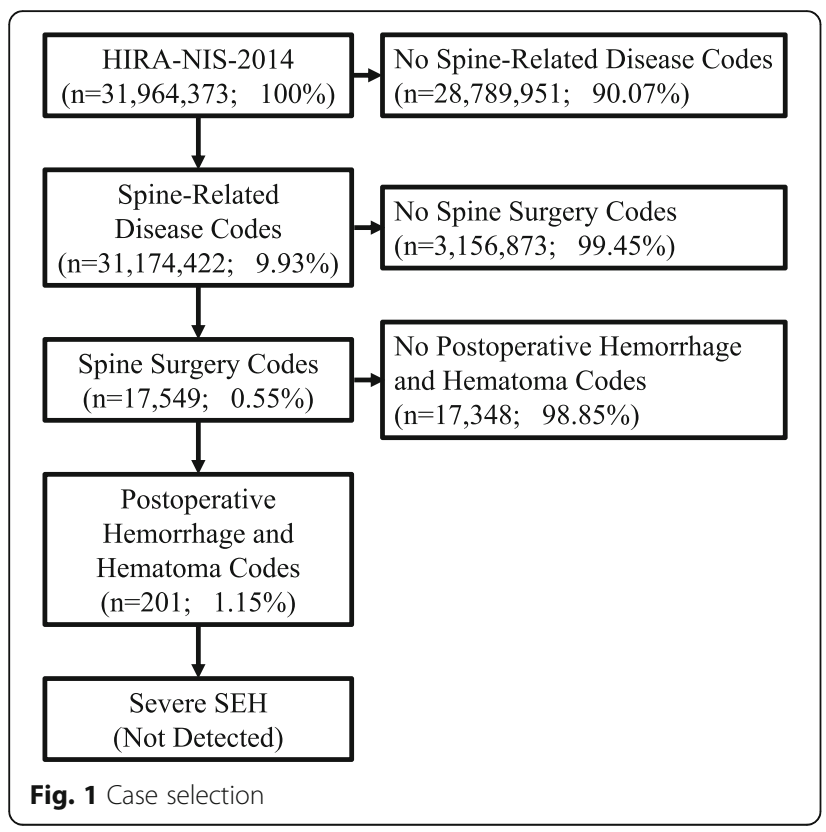

$>2 \mathrm{~h}$ in contrast to 187 patients who underwent surgery for $\leq 2 \mathrm{~h}$. Regarding blood loss, 135 patients were reported to have no blood loss in the claims dataset, and 41 had $<0.5 \mathrm{~L}$ of blood loss in the $\mathrm{SEH}$ group. Others experienced a blood loss of $>0.5 \mathrm{~L}(N=25)$. Most spine surgery procedures wherein SEH occurred $(N=139)$ were performed at small hospitals, whereas only few such procedures $(n=63)$ were performed in general hospitals. The results of the detailed descriptive analyses are shown in Table 2.

\section{SEH risk factors}

A pairwise correlation analysis that was performed before the univariate analysis revealed that there was no significant correlation among the independent variables. In the univariate analysis, we found that most independent variables that have been included in the study model were associated with the incidence rate of SEH. The following variables were found to have a statistically significant relationship with SEH. Age $(p=0.03)$, total medical cost $(p<0.001)$, lumbar spine surgery $(p<0.001)$, anterior-approach surgery $(p<0.001)$, hypertension $(p=$ $0.01)$, use of NSAIDs $(p=0.01)$, bleeding factors $(p<$ $0.001)$, surgical time $>2 \mathrm{~h}(p<0.001)$, blood loss $>0.5 \mathrm{~L}$ $(p<0.001)$, number of hospital beds $>200(p=0.03)$, and hospitals located in the rural areas. The variables with marginal significance $(0.05 \leq p<0.20)$, such as sex, infections, and small hospital types, were also included in the multivariable logistic regression model. The use of anticoagulant was not found to be a significant risk factor as per the univariate analysis, however, we included the variable in the multivariate analysis since other extant studies demonstrated it as a strong risk factor of SEH. Table 3 presents the results of the univariate analysis. Lumbar spine surgery, blood loss $>0.5 \mathrm{~L}$, surgery $>2 \mathrm{~h}$, hypertension, use of NSAIDs, presence of bleeding factors, small hospitals, and location of the hospital were identified as risk factors for SEH. However, anterior approach and anticoagulant use showed a protective effect on SEH incidence. The analyses of the survey data included the calculation of sampling weights, which ensured about $95 \%$ of concordance of the patient sample dataset with the actual population [21]. The details on the results of the multivariate analysis are presented in Table 4. The analysis results from the non-weighted dataset are provided in Supplement Table 2.

\section{Discussion}

\section{SEH case estimation}

This is the first study to utilize a national database of Korean population to investigate the incidence and risk factors of SEH. Of total 17,549 cases of spine surgery, $201(1.15 \%)$ were found to be the case of symptomatic 
Table 1 Incidence rate and risk factors in previous literature

\begin{tabular}{|c|c|c|c|c|}
\hline Authors & Year & $\begin{array}{l}\text { Incidence (cases/total } \\
\text { population) }\end{array}$ & Risk factors & $\boldsymbol{P}$-value \\
\hline Kou et al. [27] & 2002 & NA & Multilevel procedure & 0.037 \\
\hline \multirow[t]{6}{*}{ Anno et al. [28] } & 2019 & $0.42 \%(14 / 3371)$ & Presence of preoperative coagulopathy & $<0.001$ \\
\hline & & Cervical: $0.47 \%$ (4/856) & Age & NA \\
\hline & & Thoracic: 0.60\% (2/332) & Multilevel procedure & NA \\
\hline & & Lumbar: 0.37\% (8/2183) & Scar tissue due to previous spinal surgery & NA \\
\hline & & & Heparinization & NA \\
\hline & & & Vessel damage & NA \\
\hline Kebaish et al. [29] & 2004 & $0.2 \%$ & NA & NA \\
\hline \multirow[t]{2}{*}{ Yamada et al. [30] } & 2015 & $0.39 \%(32 / 8250)$ & $\begin{array}{l}\geq 50 \mathrm{mmHg} \text { increase in blood pressure after } \\
\text { extubation }\end{array}$ & 0.03 \\
\hline & & & Obesity & 0.018 \\
\hline Agnelli et al. [31] & 1999 & $0 \%(0 / 15)$ & & \\
\hline \multirow[t]{6}{*}{ Gerlach et al. [32] } & 2004 & $0.7 \%(13 / 1954)$ & Thrombocytopenia & NA \\
\hline & & & Anticoagulant use & NA \\
\hline & & & Antiplatelet agent use & NA \\
\hline & & & Alcohol consumption & NA \\
\hline & & & Coagulopathy & NA \\
\hline & & & Malignancy & NA \\
\hline \multirow[t]{5}{*}{ Uribe et al. [33] } & 2003 & $0.22 \%(9 / 4018)$ & Thrombocytopenia & NA \\
\hline & & & Coagulation factor deficiency & NA \\
\hline & & & Medications that predispose to bleeding & NA \\
\hline & & & $\begin{array}{l}\text { Previous surgery with attendant scarring at the } \\
\text { site of epidural hematoma }\end{array}$ & NA \\
\hline & & & Diabetes & \\
\hline \multirow[t]{5}{*}{ Kim et al. [34] } & 2019 & 23.6\% (94/304; diagnosed by MRI) & Anticoagulant use & $<0.001$ \\
\hline & & $\begin{array}{l}1.97 \% \text { ( } 6 / 304 \text {; hematoma } \\
\text { evacuation surgery) }\end{array}$ & Female sex & 0.012 \\
\hline & & & Old age (> 70 years) & 0.025 \\
\hline & & & Use of intraoperative water infusion pump & 0.003 \\
\hline & & & Type of operation & 0.01 \\
\hline \multirow[t]{8}{*}{ Ohba et al. [35] } & 2017 & $0.468 \%(6 / 1282)$ & Hypertension & NA \\
\hline & & & Age $>60$ years & NA \\
\hline & & & Anticoagulant use & NA \\
\hline & & & $\begin{array}{l}\text { Use of nonsteroidal anti-inflammatory } \\
\text { drugs (NSAIDs) }\end{array}$ & NA \\
\hline & & & Previous spine surgery & NA \\
\hline & & & Multilevel procedure & NA \\
\hline & & & Blood loss $>1 \mathrm{~L}$ & NA \\
\hline & & & Infections & NA \\
\hline \multirow[t]{2}{*}{ Goldstein et al. [36] } & 2013 & $1.5 \%(8 / 529)$ & $\begin{array}{l}\text { Use of nonsteroidal anti-inflammatory } \\
\text { drugs (NSAIDs) }\end{array}$ & 0.24 \\
\hline & & & Increase in Charlson Comorbidity Index & 0.003 \\
\hline \multirow[t]{3}{*}{ Yi et al. [37] } & 2006 & $0.28 \%(9 / 3270)$ & Coagulopathy & \\
\hline & & & Anticoagulant use & \\
\hline & & & Cancer & \\
\hline
\end{tabular}


Table 1 Incidence rate and risk factors in previous literature (Continued)

\begin{tabular}{|c|c|c|c|c|}
\hline Authors & Year & $\begin{array}{l}\text { Incidence (cases/total } \\
\text { population) }\end{array}$ & Risk factors & $\boldsymbol{P}$-value \\
\hline \multirow[t]{4}{*}{ Thiele et al. [38] } & 2008 & NA & Predisposed bleeding & NA \\
\hline & & & Prolonged surgical time & NA \\
\hline & & & Old age & NA \\
\hline & & & Trauma & NA \\
\hline \multirow[t]{6}{*}{ Knusel et al. [39] } & 2019 & $0.27 \%(206 / 75,878)$ & Old age & NA \\
\hline & & & Obesity (BMI > 35) & NA \\
\hline & & & Transfusion & NA \\
\hline & & & Multilevel procedure & NA \\
\hline & & & Invasive procedure & NA \\
\hline & & & Microscope use & NA \\
\hline
\end{tabular}

NA not available

SEH, and there was no case of severe SEH detected leading to continuous nerve damage and reoperation.

So far, only few studies have assessed the topic of SEH in the Asian population [12, 40-43], where the reported incidence of SEH with nerve deficit ranges from 0.1 to $0.9 \%$. Imajo et al. utilized a series of nationwide survey results on the complications among Japanese patients who underwent spine surgery from 1994 to $2001(N=$ 31,380 ) and reported SEH incidence rate of $0.9 \%$, whereas Anno et al. reported an incidence rate of $0.4 \%$ based on data from a single-center [43]. They found that SEH had a positive association with prolonged surgical time, intraoperative blood loss, and old age. The lumbar procedure was also identified as a risk factor in a previous study, and the neurological outcome was found to be poor in two cases.

Yamada et al. reported that postoperative SEH evacuation was performed in 32 of 8250 patients at their institution, out of which 14 patients developed severe paralysis [44]. The patients who underwent SEH evacuation within $24 \mathrm{~h}$ of the onset of symptoms had better clinical outcomes. The duration of onset for SEH symptoms ranged from $3 \mathrm{~h}$ to 3 days, and the median duration was $24 \mathrm{~h}$ after the initial surgery. The duration of SEH evacuation ranged from $2 \mathrm{~h}$ to 5 days after the onset of the symptoms. Yi et al. analyzed 3720 spine surgery cases over a period of 7 years (1998-2005) at a single institution in Korea and reported nine cases $(0.24 \%)$ of severe neurologic deterioration requiring surgical decompression [42]. Lumbar spine surgery, anticoagulation therapy, and highly vascularized tumor were also reported as the risk factors of SEH. Better clinical outcomes have been consistently noted in patients who undergo early intervention to evacuate SEH.

There were no cases of reoperation for hemorrhage removal or neurological deterioration due to SEH in our analytic dataset, which could be explained based on the following reasoning. In Korea, the period of hospitalization after spine surgery is more than threefold longer than that in other countries [45]. The average duration of hospital stay for our patient sample was 13.48 days, which is more than three-fold longer than the international average of 4 days [46]. The SEH group showed a longer hospital stay at 19.35 days, and the medical care team might have had adequate time to detect the potential development of epidural hemorrhage. Therefore, postoperative hemorrhage and hemorrhage were estimated to develop in $1.15 \%$ of the total patients; this incidence is higher than that in similar ethnic groups based on the literature. However, the incidence of severe SEH requiring reoperation was minimal.

Our analysis of the risk factors of SEH confirmed previous findings that the anterior-approach, lumbar surgery, intraoperative blood loss, prolonged surgical time, high blood pressure, use of NSAIDs, and concurrent bleeding factors are associated with SEH. Moreover, the type and location of the hospital were also found to be associated with the risk of SEH, which could suggest that the differences in the medical service quality based on the location of the hospitals could lead to different surgical outcomes. Inconsistent quality of inter-institution and inter-nation medical care has been a major global concern [46].

In our univariate analysis, anticoagulant use was an insignificant risk factor of SEH $(p=0.51)$. However, the use of anticoagulant and/or antiplatelet agents has been considered as one of the most important triggers for SEH incidence as reported previously $[8,42,47,48]$. Subsequently, the use of anticoagulant was incorporated in the multivariate analysis to demonstrate its effects on postoperative hemorrhage and hematoma, which showed no statistical $(p=0.08$; OR $=0.66[0.42-1.05])$.

Postoperative thromboprophylaxis is applied only to $7.89 \%$ of patients undergoing spine surgery in Korea 
Table 2 Case demographic and disease characteristics

\begin{tabular}{|c|c|c|c|}
\hline Characteristics & No SEH & SEH & Total \\
\hline Number of Cases & 17,348 & 201 & 17,549 \\
\hline Age (mean (SD) in year) & $56.72(15.12)$ & $59.08(13.71)$ & $56.75(15.11)$ \\
\hline \multicolumn{4}{|l|}{ Sex } \\
\hline Male & 8730 & 90 & 8820 \\
\hline Female & 8618 & 111 & 8729 \\
\hline Total Medical Payment ${ }^{\mathrm{a}}$ (mean (SD) in USD) & $2438(2071)$ & 3028 (2099) & 2445 (2072) \\
\hline Duration of Hospital Stay (mean (SD) in days) & $13.41(9.49)$ & $19.35(11.66)$ & $13.48(9.54)$ \\
\hline \multicolumn{4}{|l|}{ Insurance Types } \\
\hline National Health Insurance & 16,278 & 185 & 16,463 \\
\hline Medical Aid \& Veterans & 1070 & 16 & 1086 \\
\hline \multicolumn{4}{|l|}{ Spine Surgery Types (\%) } \\
\hline Lumbar & $12,381(98.64)$ & $170(1.35)$ & $12,551(100)$ \\
\hline Not Lumbar & 4967 (99.38) & $31(0.62)$ & $4998(100)$ \\
\hline \multicolumn{4}{|l|}{ Spine Surgery Approach (\%) } \\
\hline Anterior & 3918 (98.47) & $61(1.53)$ & 3979 (100) \\
\hline Not Anterior & 13,430 (98.97) & $140(1.03)$ & $13,570(100)$ \\
\hline \multicolumn{4}{|l|}{ Infections } \\
\hline No & 15,983 & 180 & 16,163 \\
\hline Yes & 1365 & 21 & 1386 \\
\hline \multicolumn{4}{|l|}{ Diabetes } \\
\hline No & 15,629 & 177 & 15,806 \\
\hline Yes & 1719 & 24 & 1743 \\
\hline \multicolumn{4}{|l|}{ Hypertension } \\
\hline No & 11,972 & 121 & 12,093 \\
\hline Yes & 5376 & 80 & 5456 \\
\hline \multicolumn{4}{|l|}{ Use of NSAIDs } \\
\hline No & 803 & 2 & 805 \\
\hline Yes & 16,545 & 199 & 16,744 \\
\hline \multicolumn{4}{|l|}{ Invasive Procedures ${ }^{\mathrm{b}}(\%)$} \\
\hline No & 13,056 (98.89) & $146(1.11)$ & $13,202(100)$ \\
\hline Yes & 4292 (98.73) & $55(1.27)$ & $4347(100)$ \\
\hline \multicolumn{4}{|l|}{ Bleeding Factors ${ }^{\complement}$} \\
\hline No & 14,223 & 140 & 14,363 \\
\hline Yes & 3125 & 61 & 3186 \\
\hline \multicolumn{4}{|l|}{ Trauma } \\
\hline No & 16,499 & 188 & 16,687 \\
\hline Yes & 849 & 13 & 862 \\
\hline \multicolumn{4}{|l|}{ Anticoagulant Use } \\
\hline No & 15,090 & 178 & 15,268 \\
\hline Yes & 2258 & 23 & 2281 \\
\hline \multicolumn{4}{|l|}{ Surgery Hours } \\
\hline $0<\mathrm{HR} \leq 2$ & 17,149 & 187 & 17,336 \\
\hline Over $2 \mathrm{~h}$ & 199 & 14 & 213 \\
\hline
\end{tabular}

Blood Loss 
Table 2 Case demographic and disease characteristics (Continued)

\begin{tabular}{|c|c|c|c|}
\hline Characteristics & No SEH & SEH & Total \\
\hline No Loss & 14,526 & 135 & 14,661 \\
\hline $0<$ Loss $\leq 0.5 \mathrm{~L}$ & 1871 & 41 & 1912 \\
\hline Over $0.5 \mathrm{~L}$ & 951 & 25 & 976 \\
\hline \multicolumn{4}{|l|}{ Type of Hospitals ${ }^{d}(\%)$} \\
\hline General Hospitals & $6371(99.04)$ & $62(0.96)$ & $6433(100)$ \\
\hline Small Hospitals & 10,977 (98.93) & $139(1.07)$ & $11,116(100)$ \\
\hline \multicolumn{4}{|c|}{ Number of Beds in Hospitals (\%) } \\
\hline Beds $\leq 200$ & 10,611 (98.99) & $108(1.01)$ & $10,719(100)$ \\
\hline More than 200 Beds & $6737(98.64)$ & $93(1.36)$ & $6830(100)$ \\
\hline \multicolumn{4}{|l|}{ Location of Hospitals (\%) } \\
\hline Metropolitan area (Seoul) & $5066(99.37)$ & $32(0.63)$ & $5098(100)$ \\
\hline Other Metropolitan areas & $8853(99.05)$ & $86(0.95)$ & $8939(100)$ \\
\hline Rural Area & $3421(97.63)$ & $83(2.37)$ & $3504(100)$ \\
\hline Total (cases) & & & \\
\hline
\end{tabular}

SEH spinal epidural hemorrhage and hematoma, NSAIDs non-steroidal anti-inflammatory drugs

${ }^{a}$ Total medical payments: The sum of the payments that patients pay for all medical services when they leave from a hospital

b Invasive procedures: lumbar puncture, myelography, and epidural anesthesia

'Bleeding factors: coagulation factor deficiency and thrombocytopenia

${ }^{\mathrm{d}}$ Type of Hospitals: The hospitals are classified into four categories in Korea, based on their function and size. From largest to smallest, they are tertiary general

hospital, general hospital, hospital, and clinic. Small hospitals include hospital and clinic. General hospitals includes tertiary general and general hospitals

Table 3 Univariate analysis result of variables

\begin{tabular}{lc}
\hline Variables & $\boldsymbol{P}$-value \\
\hline Age & 0.03 \\
Sex & $0.12 \neq$ \\
Total medical cost & 0.00 \\
Duration of hospital stay & 0.00 \\
Insurance types & $0.24 \dagger$ \\
Spine surgery type: lumbar & 0.00 \\
Spine surgery approach: anterior & 0.00 \\
Infection & $0.18 \neq$ \\
Diabetes & $0.34 \dagger$ \\
Hypertension & 0.01 \\
Use of NSAIDs & 0.01 \\
Invasive procedures & $0.39 \dagger$ \\
Bleeding factors & 0.00 \\
Trauma & $0.31 \dagger$ \\
Anticoagulant use & $0.51 \dagger$ \\
Surgical time: > 2h & 0.00 \\
Blood loss: > 0.5 L & 0.00 \\
Type of hospital: small hospitals & $0.09 \neq$ \\
Number of hospital beds: > 200 & 0.03 \\
Location of hospital: rural area & 0.00 \\
\hline
\end{tabular}

*Variables with a dagger ( $\dagger$ ) mean that the $P$-value of the corresponding variable is not statistically significant. Variables with a double dagger ( $¥)$ means that the $P$-value of the corresponding variable is located between 0.05 and 0.20 , indicating marginal significance. A $P$-value of 0.00 indicates a $P$-value $<0.001$ compared to $56.3 \%$ of the patients in North America. The apprehension against the use of anticoagulant because of suspected incidence of severe SEH might be the reason for the differences in the results in our analysis. However, thromboprophylaxis with optimal dose has been known to have no negative effect on the incidence of SEH [49]. As the preparation of thromboprophylaxis protocol has been incorporated into the hospital accreditation evaluation in Korea, standardized and

Table 4 Multivariable logistic regression results

\begin{tabular}{lcc}
\hline Risk factors & $\boldsymbol{P}>|z|^{*}$ & $\mathrm{OR}(95 \% \mathrm{Cl})$ \\
\hline Spine surgery approach: anterior & 0.03 & $0.43(0.20-0.90)$ \\
Spine surgery type: lumbar & 0.01 & $1.75(1.15-2.65)$ \\
Blood loss: $>$ 0.5 L & 0.00 & $2.11(1.31-3.41)$ \\
Surgical time: $>$ 2 h & 0.00 & $7.22(3.82-13.67)$ \\
Hypertension & 0.03 & $1.41(1.04-1.90)$ \\
Use of NSAIDs & 0.01 & $7.30(1.70-31.44)$ \\
Bleeding factors & 0.00 & $1.92(1.41-2.62)$ \\
Anticoagulant use & 0.08 & $0.66(0.42-1.05)$ \\
Type of hospital: small hospitals & \\
Location of hospital: rural area & 0.03 & $1.48(1.05-2.08)$ \\
\hline
\end{tabular}

$O R$ odds ratio, $\mathrm{Cl}$ confidence interval

${ }^{*} P$-value of 0.00 is $p$-value $<0.001$.

${ }^{a}$ In the Korean health care system, the hospitals are classified into four categories, based on their function and size. From largest to smallest, they are tertiary general hospital, general hospital, hospital, and clinic. Small hospitals include hospital and clinic 
optimized thromboprophylaxis might be considered in qualified patients without contraindication [19].

Our study attempts to fill the existing gap in the data on SEH. This is the first study examining the risk factors of SEH based on a national insurance database. Previous analyses and reports were based on single-center data and on an availability basis. Consequently, the findings of our study on the risk factors of SEH could help clinicians make suitable clinical decisions for patients undergoing spine surgery. Moreover, these data from this pilot study can be utilized for further studies on SEH and for the development of an exclusive disease code for SEH.

Although our study makes a significant contribution to the literature, the absence of an exclusive disease code for SEH in KOICD-6 is its limitation. The study attempted to overcome this constraint that exists in the national insurance database by utilizing disease/treatment codes and interventions for severe cases of SEH. Although the HIRA-NIS dataset is derived from the national claims data, it only contains information on treatments being used during hospitalization, and does not provide the exact administration time. Further studies focused at bridging these gaps are strongly encouraged.

\section{Conclusions}

We analyzed the incidence and the risk factors of SEH after spine surgery in patients in Korea by utilizing rigorous nationwide insurance data for the first time. Given that SEH is a rare complication of spine surgery and an important research area that is yet to be studied, our study makes a meaningful contribution to both the academic and medical fields by identifying the risk factors of SEH. Based on the major findings of our study, the use of anticoagulant showed no significant effect on the incidence of SEH. However, extended surgery time, intraoperative blood loss, use of NSAIDs, and preexisting bleeding factors need to be carefully evaluated in patients undergoing spinal surgery. Additionally, further studies to obtain more knowledge regarding any additional risk factors and incidence rate of SEH are warranted.

\section{Supplementary information}

Supplementary information accompanies this paper at https://doi.org/10. 1186/s12891-020-03337-8.

Additional file 1: Table S1. Disease or treatment codes. Table S2. Multivariable logistic regression results (Non-Weighted).

\section{Acknowledgements}

We would like to thank Editage (www.editage.co.kr) for English language editing.

\section{Authors' contributions}

All authors made significant contributions to this study and manuscript in general. Specific contributions are listed below: Conception and design of the study: JHP. Drafting manuscript: JHP. Data collection and preparation of datasets: JHP and SP. Statistical analysis: JHP and SP. Interpretation of results: JHP and SAC. Critical review and revision to manuscript: JHP and SAC. Final approval: all authors (JHP, SP, and SAC).

\section{Funding}

This study has been funded by the National Research Foundation of Korea (2019R1A6A1A03031807). The article processing fee would be expensed using the funding received.

\section{Availability of data and materials}

The data that support the findings of this study are available in HIRA, but restrictions apply to the availability of these data, which were used under license for the current study. Thus, these data are not publicly available. However, the data are available from HIRA upon reasonable request and with permission.

\section{Ethics approval and consent to participate}

The Korea University Institutional Review Board granted exemption for the study (application ID: KU-IRB-17-EX-241-A-1) on November 2, 2017.

\section{Consent for publication}

As this study is an analysis of secondary data set, it does not require consent for publication.

\section{Competing interests}

The authors declare no conflict of interest or have no financial disclosures concerning the materials and methods utilized in this research or the findings of this article.

\section{Author details}

${ }^{1}$ College of Pharmacy, Korea University, 2511 Sejong-ro, Sejong-si 30019, South Korea. ${ }^{2}$ Research Institute of Pharmaceutical Sciences and Technology, Korea University College of Pharmacy, 2511 Sejong-ro, Sejong-si 30019, South Korea.

Received: 12 November 2019 Accepted: 8 May 2020

Published online: 25 May 2020

\section{References}

1. Kobayashi K, Ando K, Nishida Y, Ishiguro N, Imagama S. Epidemiological trends in spine surgery over 10 years in a multicenter database. Euro Spine J. 2018;27(8):1698-703. https://doi.org/10.1007/s00586-018-5513-4.

2. Szpalski M, Gunzburg R, Melot C, Aebi M. The aging of the population: a growing concern for spine care in the twenty-first century. Euro Spine J. 2003;12(Suppl 2):S81-3. https://doi.org/10.1007/s00586-003-0592-1.

3. Lillemae K, Jarvio J, Silvasti-Lundell MK, Antinheimo J, Hernesniemi J, Niemi $\Pi$. Incidence of postoperative hematomas requiring surgical treatment in neurosurgery: a retrospective observational study. World Neurosurg. 2017; 108:491-7. https://doi.org/10.1016/j.wneu.2017.09.007.

4. Schroeder GD, Kurd MF, Kepler CK, Arnold PM, Vaccaro AR. Postoperative epidural hematomas in the lumbar spine. J Spinal Disord Tech. 2015;28(9): 313-8. https://doi.org/10.1097/BSD.0000000000000329.

5. Ross JS, Masaryk TJ, Modic MT, Bohlman H, Delamater R, Wilber G. Lumbar spine: postoperative assessment with surface-coil MR imaging. Radiology. 1987;164(3):851-60. https://doi.org/10.1148/radiology.164.3.3615887.

6. Dina T, Boden S, Davis D. Lumbar spine after surgery for herniated disk: imaging findings in the early postoperative period. AJR Am J Roentgenol. 1995;164(3):665-71.

7. Luo XB, Zhou X, Wang Q, Cai XJ, Luo ZP, Ma YZ. The classification of recurrent spinal epidural hematoma: a review of the literature and a comparison with the cases. Euro Spine J. 2016;25(Suppl 1):224-9. https://doi. org/10.1007/s00586-016-4506-4

8. Kim JE, Choi DJ, Park E. Evaluation of postoperative spinal epidural hematoma after Biportal endoscopic spine surgery for single-level lumbar spinal stenosis: clinical and magnetic resonance imaging study. World Neurosurg. 2019. https://doi.org/10.1016/j.wneu.2019.02.150.

9. Korean Information Center for Disease. Disease codes status of admission and outpatient treatment Aug 16, 2018. http://www.koicd.kr/2016/stats/ diseaseStats.do. Accessed 16 Aug 2018. 
10. Oecd. Strengthening Health Information Infrastructure for Health Care Quality Governance. 2013.

11. Bovonratwet P, Fu MC, Tyagi $V$, et al. Incidence, risk factors, and clinical implications of postoperative hematoma requiring reoperation following anterior cervical discectomy and fusion. Spine. 2019;44(8):543-9. https://doi. org/10.1097/BRS.0000000000002885.

12. Kou J, Fischgrund J, Biddinger A, Herkowitz H. Risk factors for spinal epidural hematoma after spinal surgery. Spine. 2002;27(15):1670-3.

13. Rogers SO, Kilaru RK, Hosokawa P, Henderson WG, Zinner MJ, Khuri SF. Multivariable predictors of postoperative venous thromboembolic events after general and vascular surgery: results from the patient safety in surgery study. J Am College Surgeons. 2007;204(6):1211-21. https://doi.org/10.1016/ j.jamcollsurg.2007.02.072.

14. Kanchanabat B, Stapanavatr W, Meknavin S, Soorapanth C, Sumanasrethakul C, Kanchanasuttirak P. Systematic review and meta-analysis on the rate of postoperative venous thromboembolism in orthopaedic surgery in Asian patients without thromboprophylaxis. Br J Surg. 2011;98(10):1356-64. https://doi.org/10.1002/bjs.7589.

15. Bono CM, Watters WC, Heggeness $M H$, et al. An evidence-based clinical guideline for the use of antithrombotic therapies in spine surgery. Spine $\mathrm{J}$ 2009;9(12):1046-51. https://doi.org/10.1016/j.spinee.2009.09.005.

16. Falck-Ytter $Y$, Francis CW, Johanson NA, et al. Prevention of VTE in orthopedic surgery patients: antithrombotic therapy and prevention of thrombosis, 9th ed: American college of chest physicians evidence-based clinical practice guidelines. Chest. 2012;141(2, Supplement):e278S-325S. https://doi.org/10.1378/chest.11-2404.

17. Wang T, Yang SD, Huang WZ, Liu FY, Wang H, Ding WY. Factors predicting venous thromboembolism after spine surgery. Medicine (Baltimore). 2016: 95(52):e5776. https://doi.org/10.1097/MD.0000000000005776.

18. Leizorovicz A. Epidemiology of post-operative venous thromboembolism in Asian patients. Results of the SMART venography study. Haematologica. 2007;92(9):1194-200. https://doi.org/10.3324/haematol.10819.

19. Park JH, Lee KE, Yu YM, Park YH, Choi SA. Incidence and risk factors for venous thromboembolism after spine surgery in Korean patients. World Neurosurgery. 2019;128:e289-307. https://doi.org/10.1016/j.wneu. 2019.04.140.

20. Nieto J, Bruscas M, Ruiz-Ribo D, et al. Acute venous thromboembolism in patients with recent major bleeding. The influence of the site of bleeding and the time elapsed on outcome. J Thromb Haemost. 2006;4(11):2367-72.

21. Kim L, Kim JA, Kim S. A guide for the utilization of Health Insurance Review and Assessment Service national patient samples. Epidemiol Health. 2014; 36:e2014008. https://doi.org/10.4178/epih/e2014008.

22. Kim L, Kim JA, Kim S. A guide to the use of national patient samples. 2011. https://www.e-epih.org/journal/view.php?doi=10.4178/epih/e2014008. Accessed 19 Jan 2019.

23. Patient Sample Data Set: Health Insurance Review \& Assessment National Inpatient Sample in 2014. Health Insurance Review \& Assessment Service. http:// opendata.hira.or.kr/op/opc/selectPatDataApllnfoView.do. Accessed 14 Jan 2019.

24. Awad JN, Kebaish KM, Donigan J, Cohen DB, Kostuik JP. Analysis of the risk factors for the development of post-operative spinal epidural haematoma. J Bone Joint Surgery British Volume. 2005;87(9):1248-52. https://doi.org/10. 1302/0301-620X.87B9.16518.

25. ICD-9-CM Addenda, Conversion Table, and Guidelines. In: Center for Disease Control and Prevention/National Center for Health Statistics; 2013: https://www. cdc.gov/nchs/icd/icd9cm_addenda_guidelines.htm. Accessed 17 Aug 2018.

26. StataCorp. Stata Statistical Software: Release 15. College Station: StataCorp LLC; 2017. https://www.stata.com/support/faqs/resources/citing-softwaredocumentation-faqs/.

27. Kou J, Fischgrund J, Biddinger A, Herkowitz H. Risk factors for spinal epidural hematoma after spinal surgery. Spine. 2002;27(15):1670-3.

28. Anno M, Yamazaki T, Hara N, Ito Y. The incidence, clinical features, and a comparison between early and delayed onset of postoperative spinal epidural hematoma. Spine. 2019;44(6):420

29. Kebaish KM, Awad JN. Spinal epidural hematoma causing acute cauda equina syndrome. Neurosurgical focus. 2004;16(6):e1.

30. Yamada K, Abe Y, Satoh S, Yanagibashi Y, Hyakumachi T, Masuda T. Large Increase in Blood Pressure After Extubation and High Body Mass Index Elevate the Risk of Spinal Epidural Hematoma After Spinal Surgery. Spine. 2015;40(13):1046-52. https://doi.org/10.1097/brs.0000000000000876.

31. Agnelli G. Prevention of venous thromboembolism after neurosurgery. Thrombosis Haemostasis. 1999;82(2):925-30.
32. Gerlach R, Raabe A, Beck J, Woszczyk A, Seifert V. Postoperative nadroparin administration for prophylaxis of thromboembolic events is not associated with an increased risk of hemorrhage after spinal surgery. Eur Spine J. 2004; 13(1):9-13. https://doi.org/10.1007/s00586-003-0642-8.

33. Uribe J, Moza K, Jimenez O, Green B, Levi AD. Delayed postoperative spinal epidural hematomas. Spine J. 2003;3(2):125-9.

34. Kim JE, Choi DJ, Kim MC, Park EJ. Risk Factors of Postoperative Spinal Epidural Hematoma After Biportal Endoscopic Spinal Surgery. World Neurosurg. 2019. https://doi.org/10.1016/j.wneu.2019.05.141.

35. Ohba T, Ebata S, Haro H. Influence of postoperative hypertension on the development of spinal epidural hematoma. Orthopaedic Surg. 2017;9(4): 386-90.

36. Goldstein CL, Bains I, Hurlbert RJ. Symptomatic spinal epidural hematoma after posterior cervical surgery: incidence and risk factors. Spine J. 2015; 15(6):1179-87. https://doi.org/10.1016/j.spinee.2013.11.043.

37. Yi S, Yoon DH, Kim KN, Kim SH, Shin HC. Postoperative spinal epidural hematoma: risk factor and clinical outcome. Yonsei Med J. 2006;47(3):326-32. https://doi.org/10.3349/ymj.2006.47.3.326.

38. Thiele RH, Hage ZA, Surdell DL, Ondra SL, Batjer HH, Bendok BR. Spontaneous spinal epidural hematoma of unknown etiology: case report and literature review. Neurocrit Care. 2008;9(2):242-6. https://doi.org/10. 1007/s12028-008-9083-X.

39. Knusel K, Du JY, Ren B, Kim C-Y, Ahn UM, Ahn NU. Symptomatic epidural hematoma after elective posterior lumbar decompression: incidence, timing, risk factors, and associated complications. HSS Journal ${ }^{\circledR}$. 2019:1-8. https:// doi.org/10.1007/s11420-019-09690-2.

40. Li H, Wang Z, Xu H, Sun J, Ning G, S F. Delayed spinal epidural hematoma after posterior cervical spine surgery: a case report. Int J Clin Exp Med. 2018; 11(4):4226.

41. Kao F-C, Tsai T-T, Chen L-H, et al. Symptomatic epidural hematoma after lumbar decompression surgery. Eur Spine J. 2015;24(2):348-57. https://doi. org/10.1007/s00586-014-3297-8.

42. Yi S, Yoon DH, Kim KN, Kim SH, Shin HC. Postoperative spinal epidural hematoma: risk factor and clinical outcome. Yonsei Med J. 2006;47(3):326-32. https://doi.org/10.3349/ymj.2006.47.3.326

43. Imajo Y, Taguchi T, Yone K, et al. Japanese 2011 nationwide survey on complications from spine surgery. J Orthop Sci. 2015;20(1):38-54. https://doi. org/10.1007/s00776-014-0656-6.

44. Yamada K, Abe Y, Satoh S, Yanagibashi Y, Hyakumachi T, Masuda T. Large increase in blood pressure after Extubation and high body mass index elevate the risk of spinal epidural hematoma after spinal surgery. Spine. 2015;40(13):1046-52. https://doi.org/10.1097/brs.0000000000000876.

45. Oecd. OECD Health Statistics 2014-Frequently Requested Data. 2014.

46. Zhang $T, X u Y$, Ren J, Sun L, Liu C. Inequality in the distribution of health resources and health services in China: hospitals versus primary care institutions. Int J Equity Health. 2017;16(1):42. https://doi.org/10.1186/ s12939-017-0543-9.

47. Gerlach R, Raabe A, Beck J, Woszczyk A, Seifert V. Postoperative nadroparin administration for prophylaxis of thromboembolic events is not associated with an increased risk of hemorrhage after spinal surgery. Eur Spine J. 2004; 13(1):9-13.

48. Mclynn RP, Diaz-Collado PJ, Ottesen TD, et al. Risk factors and pharmacologic prophylaxis for venous thromboembolism in elective spine surgery. Spine J. 2017. https://doi.org/10.1016/j.spinee.2017.10.013.

49. Mosenthal WP, LM J. Thromboprophylaxis in Spinal Surgery. Spine [Spine (Phila Pa 1976)]. 2018;43(8):E474-81. https://doi.org/10.1097/BRS. 0000000000002379

\section{Publisher's Note}

Springer Nature remains neutral with regard to jurisdictional claims in published maps and institutional affiliations. 